\title{
Competências do enfermeiro: estudo em um hospital privado
}

\author{
Competencies of nurses: study in a private hospital \\ Competencias de enfermeros: estudio en un hospital privado
}

\begin{abstract}
Helaine Cristine Dias', Kely César Martins de Paiva"
' Universidade José do Rosário Vellano (UNIFENAS). Curso de Enfermagem. Centro Universitário Metodista Izabela Hendrix. Curso de Enfermagem. Belo Horizonte-MG, Brasil.

"Faculdade Novos Horizontes. Programa de Mestrado Acadêmico em Administração. Belo Horizonte-MG, Brasil.
\end{abstract}

Submissão: $15 / 09 / 2009$

Aprovação: 17/05/2011

\section{RESUMO}

Este estudo objetivou analisar como se encontram configuradas as competências gerenciais, exigidas e efetivas, dos enfermeiros de um hospital da rede privada em Belo Horizonte-MG, na percepção dos enfermeiros e de outras categorias da Enfermagem. Nesta pesquisa de campo, descritiva, com abordagem quantitativa, os dados foram coletados por meio de levantamento documental e entrevistas, os quais foram submetidos à análise documental e de conteúdo, respectivamente. Considerando-se as diversas fontes de dados utilizadas, observou-se que diferentes papéis e competências são exigidos e efetivamente realizados pelos enfermeiros, levando a questionamentos relativos às suas competências gerenciais. Ao final, foram apontadas limitações do estudo e sugestões de pesquisas futuras.

Descritores: Enfermagem; Competências gerenciais; Competência profissional.

\section{ABSTRACT}

The purpose of this study was to analyze how are configured the management competences, required and effectives, of nurses who work in a private hospital in Belo Horizonte-MG, according to the perception of nurses and other nursing categories professionals. In this field research, a descriptive one, with a quantitative approach, data were collected through a documentary survey and interviews and submitted, respectively, to documental and content analysis. Taking into consideration the several data sources that were utilized, it was observed that the different roles and competences are required and effectively performed by the nurses, leading to further questions related to their management competences. Limitations of the study were pointed as well as suggestions for further researches.

Key words: Nursing; Management competences; Professional competences.

\section{RESUMEN}

El propósito de este estudio fue analizar cómo se configuran las competencias de gerenciamiento, necesarias y efectivas, de los enfermeros que trabajan en un hospital privado de Belo Horizonte-MG, de acuerdo con la percepción de estos enfermeros y otras categorías de Enfermería. En esta investigación de campo, del tipo descriptivo, con enfoque cuantitativo, los datos fueron recogidos mediante encuesta documental y entrevistas, y sometidas, respectivamente, a análisis documental y de contenido. Teniendo en cuenta las diferentes fuentes de datos que fueran utilizadas, se observó que diferentes papéis y competencias son requeridos y efectivamente realizados por los enfermeros, lo que lleva a otras preguntas relativas a sus competencias gerenciales. Al final, son señaladas las limitaciones del estudio, así como sugerencias para investigaciones posteriores.

Palabras clave: Enfermería; Competencias gerenciales; Competencia profesional. 


\section{INTRODUÇÃO}

No século XX, precisamente a partir da década de 70, o novo modelo produtivo configurado, baseado na flexibilização dos processos e mercados de trabalho, dos produtos e padrões de consumo, exigiu um "novo" profissional que se adeque às exigências de uma nova realidade para o mercado, sendo considerada sua capacidade como ser humano, ou seja, criatividade, versatilidade, flexibilidade, capacidade de relacionar-se, comunicar-se, resolver problemas, na qual o "saber ser" dá lugar ao "saber fazer". Esse modelo estendeu-se também ao setor saúde que passou a ser encarado como relevante para o conjunto do sistema econômico. Essas transformações propõem novas relações no mercado de trabalho, novos mecanismos de gestão e exigências de novos perfis profissionais nesse setor ${ }^{(1-3)}$.

$\mathrm{Na}$ Enfermagem, verifica-se uma tendência do deslocamento do enfermeiro de áreas operacionais para áreas estratégicas da organização, enfatizando a mudança de papéis no âmbito hospitalar ${ }^{(4)}$. Isso pressupõe uma busca de qualificações por parte dos enfermeiros visando atender às novas demandas do trabalho desse profissional, abrindo-lhe novas perspectivas no mercado de trabalho diante da ampliação do escopo do seu cargo. Para muitos enfermeiros, a atuação em funções gerenciais e assistenciais representa uma situação conflituosa e de indefinição de papéis, uma vez que, ao assumirem várias atividades, torna-se impossível a priorização e conciliação dessas ${ }^{(5)}$. Muitos enfermeiros se perdem na função gerencial por não atingir o equilíbrio entre tomada de decisão e implementação das ações ${ }^{(6)}$.

O gerenciamento em enfermagem é visto como uma atividade complexa, na qual são exigidas dos profissionais competências cognitivas, técnicas e atitudinais indispensáveis à implementação de estratégias administrativas ${ }^{(6)}$. A participação do enfermeiro em cargos gerenciais decorre de conhecimentos relacionados à operacionalização do cuidado ao cliente, à capacitação na área administrativa, à habilidade de coordenar o trabalho da equipe multiprofissional e sua relação com a clientela ${ }^{(5)}$. No exercício da gerência, o enfermeiro é um intermediador das ordens médicas e da alta administração, repassando aos membros da equipe de trabalho a ideologia emanada da organização.

Diante desse contexto, pode-se resumir o problema de pesquisa da seguinte forma: o enfermeiro é um profissional cada vez mais demandado em ações de diversas naturezas, já que a face gerencial dessa profissão é marcante e a gestão, por si própria, é percebida como uma atividade ambígua e contraditória ${ }^{(7)}$. Assim, ele tem que formar e desenvolver competências que sejam capazes de manter seu desempenho em níveis satisfatórios. Esse julgamento não passa apenas pelo próprio sujeito, pois a competência envolve o reconhecimento de terceiros que, no caso dos enfermeiros, referem-se aos membros de uma equipe maior e multidisciplinar, além de outros atores sociais que participam indiretamente do seu cotidiano laboral.

Assim, consideram-se os papéis a serem desempenhados pelos enfermeiros-gestores, enquanto comportamentos esperados por eles próprios e por terceiros (inclusive subordinados), e as competências necessárias para tal desempenho, o que é contemplado no modelo de Quinn et al. ${ }^{(8)}$, escolhido como base analítica nessa pesquisa. Assim, sua questão norteadora encontra ressonância no problema de pesquisa descrito nesta introdução e pode ser resumida da seguinte forma: como se encontram configuradas as competências gerenciais, exigidas e efetivas, dos enfermeiros que atuam em um hospital da rede privada de saúde em Belo Horizonte, na percepção de enfermeiros e de outros membros da equipe de enfermagem?

Tendo em vista os aspectos abordados, esta pesquisa teve como objetivo: descrever e analisar como se encontram configuradas as competências gerenciais, exigidas e efetivas, dos enfermeiros que atuam em um hospital da rede privada de saúde em Belo Horizonte-MG, na percepção de enfermeiros e de outros membros da equipe de enfermagem.

\section{REFERENCIAL TEÓRICO}

\section{Competências Profissionais e Gerenciais}

A noção de competência ocupa um espaço ainda indefinido encarado como a forma de repensar as interações entre as pessoas, seus saberes e capacidades e, por outro lado, as organizações interligadas aos processos de trabalho essenciais e relacionais (relação com clientes, fornecedores e trabalhadores). Diante dessas considerações, a noção de competência aplica-se a capacidade de mobilizar e aplicar conhecimentos em uma determinada situação. Para que haja competência, torna-se necessário a ação de vários recursos como conhecimentos, capacidades cognitiva, capacidades integrativas, capacidades relacionais, dentre outros, os quais são testados frente aos desafios de um novo projeto, de problemas. Através da ação e do aprendizado, tem-se a oportunidade de desenvolver a própria competência(9).

Nos estudos de Vergara e Branco ${ }^{(10)}$, identifica-se a necessidade de competências requeridas aos profissionais que atuam nas organizações frente à adaptação dessas às transformações no mundo dos negócios. A competência gerencial exige o desenvolvimento de habilidades operacionais e a capacidade do gerente em lidar com as forças dentro e fora das organizações por meio do desenvolvimento de atitudes, valores e visões de mundo. Destacam-se como competências gerenciais adequadas ao atual contexto organizacional: gerir a competitividade, gerir a complexidade, gerir a adaptabilidade, gerir equipes, gerir incerteza e gerir o aprendizado(11).

Gerir competitividade relaciona-se ao conhecimento do mercado e do ambiente, do espírito empreendedor, à iniciativa e autonomia, à visão estratégica ou pensamento estratégico, ao direcionamento para resultados do negócio, ao conhecimento da tecnologia de sistemas, ao gerenciamento do desempenho e produtividade e ao conhecimento financeiro e do negócio. Gerir complexidade relaciona-se à visão global ou sistêmica, capacidade de análise e síntese, tomada de decisão, habilidade de lidar com conceitos, habilidade de negociação, flexibilidade. A competência gerir a adaptabilidade enfatiza a flexibilidade, a adaptabilidade e disposição para mudança como competências necessárias aos gerentes. A gestão da adaptabilidade implica equilíbrio emocional, 
tolerância ao estresse e à ambigüidade, energia e maturidade. A criatividade como habilidade em buscar soluções inovadoras voltadas para métodos e processos também se refere à gestão da adaptabilidade. Mesmo com essas competências reconhecidas nos gerentes, ressalta-se a competência gerir equipes como necessária para o alcance organizacional ${ }^{(10)}$.

Para a competência gerir equipes, ressalta-se a necessidade do trabalho em equipe que envolve a delegação e o empowerment, a capacidade de liderar por meio da habilidade de mobilizar e influenciar pessoas, motivando-as para o alcance dos objetivos e pela capacidade de comunicar uma visão clara do negócio atingindo comprometimento. A habilidade de relacionamento interpessoal, empatia interpessoal e influência. Essas competências estão relacionadas às aptidões atitudinais e comportamentais ${ }^{(10)}$.

Em se tratando da competência gerir a incerteza, esta se relaciona à capacidade de julgamento, perspicácia, percepção, transparência nas ações, ética profissional, consistência pessoal. A competência gerir o aprendizado direciona-se ao autodesenvolvimento voltado para o crescimento pessoal e profissional, capacidade em manter-se informado e agilidade para novas aprendizagens bem como a capacidade quanto ao desenvolvimento das pessoas para obtenção de vantagem competitiva $^{(10)}$.

Contata-se que as competências requeridas aos gerentes das empresas estudadas por Vergara e Branco(10) são congruentes em relação aos pontos de vista, o que indica o reconhecimento de ameaças e oportunidades comuns enfrentadas pelas organizações. Isso demonstra que, frente ao contexto em que os gerentes atuam, as competências não se isolam, diversas competências são necessárias para a sua atuação.

Nesse sentido, as competências profissionais específicas (cognitiva, funcional, comportamental, ética e política) podem atuar concomitantemente de maneira a promover manifestação efetiva da competência profissional ${ }^{(12)}$. No caso de profissionais que têm assumido funções gerenciais, como os enfermeiros, tais competências circunscrevem-se de particularidades, tendo em vista os papéis a serem desempenhados em contextos muito específicos, como é o caso da saúde no Brasil. Torna-se relevante, então, apresentar e discutir o modelo adotado na pesquisa, tendo em vista contemplar papéis gerenciais diferenciados cujo desempenho depende de certas competências, conforme será descrito a seguir.

\section{Modelo de Competências Gerenciais de Quinn e colaboradores}

De acordo com Quinn et al. ${ }^{(8)}$, atingir a eficácia organizacional num ambiente dinâmico tornou-se um desafio. Em meados da década de 1990, os autores concluem pela inexistência de um modelo único que oriente os gerentes na consecução dos objetivos organizacionais, sendo necessário abordar quatro modelos de gestão em uma matriz mais ampla, considerando o foco (interno ou externo) e nível de institucionalização de processos (flexibilidade ou controle). Assim, classificam os modelos gerenciais como: metas racionais, processos internos, relações humanas e sistemas abertos. Isoladamente, nenhum desses modelos proporciona a eficácia organizacional. É necessário considerá-los como parte de um arcabouço maior, chamado de "quadro de valores competitivos". Os modelos estão relacionados em dois eixos: o eixo vertical que vai da flexibilidade (em cima) ao controle (embaixo) e o eixo horizontal que vai do foco organizacional interno (esquerda) ao foco organizacional externo (direita). Cada modelo é inserido em um dos quadrantes. O modelo das relações humanas enfatiza os critérios de participação, abertura, compromisso e moral. Os critérios enfatizados no modelo dos sistemas abertos são inovação, adaptação, crescimento e aquisição de recursos. O modelo de metas racionais enfatiza direção, clareza de objetivos, produtividade e realização. Os critérios relacionados à documentação, gerenciamento de informações, estabilidade e controle são enfatizados no modelo de processos internos. Além dos critérios destinados a cada meta, alguns valores gerais figuram no perímetro externo.

Deste modo, cada modelo se relaciona a um oposto. O modelo das relações humanas, relacionado à flexibilidade $\mathrm{e}$ foco interno, estabelece contraste com o modelo das metas racionais, definido pelo controle e foco externo; o dos sistemas abertos, direcionado à flexibilidade e foco externo, contrasta com o modelo dos processos internos, definido pelo controle e foco interno. O modelo das relações humanas considera que as pessoas possuem um valor inerente, já no de metas racionais, as pessoas adquirem valor a partir de uma contribuição significativa para o cumprimento das metas. Nos sistemas abertos, este cuida da adaptação à contínua transformação do ambiente, enquanto o modelo dos sistemas internos visa à manutenção da estabilidade e continuidade no sistema ${ }^{(8)}$.

Esses quatro modelos compõem o modelo gerencial de Quinn et al. ${ }^{(8)}$, intitulado como "quadro de valores competitivos", conforme visualizado na Figura 1.

Flexibilidade e Autonomia

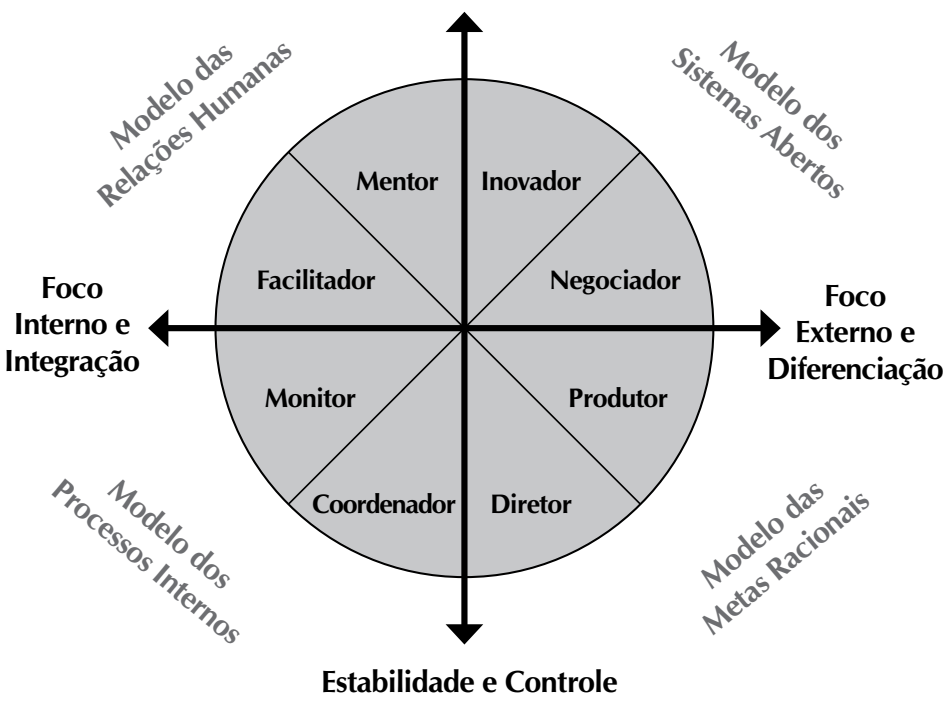

Figura 1 - Modelos de Gestão e Papéis Gerenciais, segundo Quinn e colaboradores (Adaptado de Quinn et al. $\left.{ }^{(8)}\right)$. 
Diante desses extremos, ao comparar um modelo em relação ao outro, a tendência é a desvalorização de um ou outro, o que comprova a necessidade de um bom desempenho nos quatro modelos concomitantemente, proporcionando elevada efetividade à estratégia gerencial. Ressalta-se que cada modelo aponta para os benefícios de estratégias diferentes e até contrárias. Essa estrutura constitui-se em uma ferramenta que tem como abordagem a ampliação do pensamento com foco na escolha e na eficácia. Para que essa ferramenta seja útil, deve-se seguir três passos: apreciar vantagens e desvantagens de cada modelo, adquirir e utilizar as competências de cada modelo, integrar as competências de cada modelo de acordo com a situação gerencial encontrada ${ }^{(8)}$.

Considerando o foco na eficácia do gestor, especificam-se papéis que podem ser experimentados por um gerente em cada um dos modelos ${ }^{(8)}$. No modelo das metas racionais, os papéis são de diretor e produtor; nos processos internos, são de monitor e coordenador; no modelo das relações humanas, os papéis são de facilitador e de mentor e nos sistemas abertos, de inovador e negociador. Cada papel compreende três competências gerenciais básicas que ao mesmo tempo complementam aquelas com que fazem fronteira e contrastam com aquelas que se opõem. Quinn et al. ${ }^{(8: 25)}$ as descrevem da seguinte forma: Inovador (convívio com a mudança, pensamento criativo, gerenciamento da mudança); Negociador (constituição e manutenção de uma base de poder; negociação de acordos e compromissos; apresentação de idéias); Produtor (produtividade do trabalho; fomento de um ambiente de trabalho produtivo; gerenciamento do tempo e do estresse); Diretor (desenvolvimento e comunicação de uma visão; estabelecimento de metas e objetivos; planejamento e organização); Coordenador (gerenciamento de projetos; planejamento do trabalho, gerenciamento multidisciplinar); Monitor (monitoramento do desempenho individual; gerenciamento do desempenho e processos coletivos; análise de informações com pensamento crítico); Facilitador (constituição de equipes; uso de um processo decisório participativo; gerenciamento de conflitos); Mentor (compreensão de si próprio e dos outros; comunicação eficaz; desenvolvimento dos empregados).

É necessário habilidade para desempenhar os oito papéis e ter a capacidade de mesclar e equilibrar esses diferentes papéis de acordo com as exigências das circunstâncias. Para atingir a categoria de "gerentes eficazes", deve-se considerar os valores concorrentes através do uso de mentalidades diversas, o uso de competências associadas aos quatro modelos e integrar as várias competências que confrontam com a ação. Para tornar-se um gerente capaz, há sempre algo a aprender que irá desenvolver novas habilidades e, nessas circunstâncias, à medida que se avança na hierarquia organizacional, novas competências são adquiridas, "entregues", outras desaprendidas, reconhecidas, deparando-se dessa forma com novas responsabilidades e desafios ${ }^{(8)}$.

\section{METODOLOGIA}

Este estudo teve como objetivo descrever e analisar como se encontram configuradas as competências gerenciais, exigidas e efetivas, dos enfermeiros que atuam em um hospital da rede privada de saúde em Belo Horizonte-MG, na percepção de enfermeiros e de outros membros da equipe de enfermagem. Caracteriza-se esta pesquisa de campo como descritiva e com abordagem essencialmente qualitativa. A pesquisa de campo é a investigação onde ocorre ou ocorreu o fenômeno e que dispõe de elementos para explicá-lo ${ }^{(13)}$. Nesse sentido, os dados foram coletados em um hospital da rede privada de saúde, localizado em Belo Horizonte-MG. Ressalta-se que esta pesquisa foi aprovada pelo Comitê de Ética em Pesquisa (Protocolo $n^{\circ}$ 277/08) do referido hospital, tendo sido todos os respondentes noticiados a esse respeito.

Ressalte-se que a pesquisa descritiva pode estabelecer correlações entre variáveis e sua natureza, serve como base para explicação de fenômenos, embora não tenha compromisso de explicar os fenômenos que descreve, e expõe características de determinada população ${ }^{(13)}$. Os dados provenientes de métodos qualitativos consistem em descrições detalhadas de situações com o objetivo de compreender os indivíduos em seu próprio termo ${ }^{(14)}$. Esse método permitiu compreender a realidade investigada a partir de entrevistas com enfermeiros e outros membros da equipe de enfermagem.

Para a coleta de dados, procedeu-se ao levantamento documental (descrição de cargos e competências dos enfermeiros), realização de entrevistas com quatro enfermeiros e com outros seis membros da equipe de enfermagem (técnicos de enfermagem e auxiliares de enfermagem), com dois roteiros estruturados com quinze perguntas cada, espelhadas de modo a permitir a comparação de respostas entre os grupos abordados, com objetivo de levantar e aprofundar dados sobre as competências gerenciais dos enfermeiros, exigidas e efetivas. Tendo em vista a coleta de dados em fontes distintas, caracterizou-se uma triangulação de dados $^{(15)}$. Ressalta-se, ainda, que os dados foram coletados seguindo o critério de acessibilidade $^{(13)}$ aos sujeitos, mediante autorização do hospital, os quais, concordando com os termos da pesquisa, assinaram o Termo de Consentimento Livre e Esclarecido. Os sujeitos foram selecionados na medida em que os contatos foram feitos e eles se dispuseram a participar desse processo. Aqueles que se recusaram a assinar o Termo ou não foram autorizados pelo hospital, foram excluídos da pesquisa, cuja coleta de dados se deu no primeiro semestre do ano de 2009.

Quanto às técnicas para a análise de dados, os dados provenientes do levantamento documental sofreram análise documental. Já os dados das entrevistas foram tratados e analisados em três fases ${ }^{(16)}$ : preparação, tabulação quantitativa e análise ou categorização temática. Na primeira fase, as entrevistas transcritas passaram por uma análise de conteúdo. Na segunda fase, foi elaborado um quadro interpretativo cruzando as temáticas destacadas diante das entrevistas, fornecendo um quadro síntese. Através desse quadro, tornou-se possível um mapeamento do grupo entrevistado, reunindo aproximações e, após agrupamentos em uma mesma linha condutória, criou-se um eixo de análise que possibilita a identificação de perfis semelhantes. Esse quadro possibilitou uma tabulação quantitativa, e tornou-se possível obter uma visão ampliada dos dados quantificados das entrevistas com a utilização de 
estatística descritiva, apresentada em formato de tabela. $\mathrm{Na}$ terceira fase, foi realizada a construção de uma tipologia através de cortes intencionais identificados pelo conteúdo das entrevistas, permitindo uma categorização temática. Essa fase permitiu a extração de temas e ideias que extrapolaram o roteiro de entrevista e que se manifestaram nos entrevistados como alvo de preocupação merecendo devida atenção para construção de uma planilha temática.

Convém ressaltar que a técnica de análise de conteúdo foi a técnica-chave para a análise dos dados. A análise de conteúdo é um conjunto de técnicas de análise das comunicações ${ }^{(17)}$, por meio de procedimentos sistemáticos e objetivos da descrição do conteúdo das mensagens. O interesse dessa técnica reside na interpretação dos dados tratados, transformados em saberes que podem ser de natureza psicológica, sociológica, histórica, econômica, dentre outras. Visa também obter conteúdo de indicadores (quantitativos ou não) que permitam aquisição de conhecimentos relativos às variáveis inferidas da mensagem. A análise de conteúdo possui duas funções: função heurística e função de "administração da prova"(17). A função heurística enriquece a tentativa exploratória e favorece a propensão à descoberta. A função de "administração da prova" utiliza-se de hipóteses que servirão ao método de análise sistemática para verificação de confirmação de uma afirmação. As duas funções podem ser complementares. A análise de conteúdo é considerada como um método formal para pesquisas qualitativas, uma vez que o texto analisado é convertido em variáveis numéricas para análise quantitativa de dados em termos de reincidência das percepções dos sujeitos ${ }^{(15)}$.

\section{RESULTADOS E DISCUSSÃO}

\section{O hospital $X$ e as competências exigidas dos enfermeiros}

O hospital $X$ é uma instituição hospitalar sem fins lucrativos, com atendimento em diversas especialidades clínicas; possui mais de 300 leitos distribuídos em apartamentos e enfermarias. Conta com um quadro funcional total de aproximadamente 1500 funcionários, sendo 764 funcionários da enfermagem (92 enfermeiros e 672 técnicos de enfermagem e auxiliares de enfermagem).

Existem, no hospital X, 45 setores onde o enfermeiro pode atuar,e 3 cargos ocupados apenas por enfermeiros (gerente, coordenador e enfermeiro), todos descritos e analisados, incluindo-se a descrição de todas as competências necessárias ao desempenho das tarefas e atribuições prescritas. Contabilizando-se tais diferenciações, foram disponibilizadas dezenove descrições de cargos e competências, e apenas três dessas descrições não foram disponibilizados para este artigo. Após leitura de todas as descrições e competências dos cargos ocupados por enfermeiros, verificou-se a predominância do papel de monitor em relação aos demais, tendo em vista o alinhamento de cada competência de cada cargo exercido por enfermeiro no hospital a um dos papéis do modelo adotado ${ }^{(8)}$.

Além do papel de monitor, percebeu-se que os papéis de produtor e o de mentor, e as respectivas competências, são os mais requeridos formalmente dos enfermeiros no hospital $X$. Isso implica que o modelo de gestão está mais direcionado para o controle do que para flexibilidade e parece ser o prescrito institucionalmente para a atuação dos enfermeiros de modo geral neste hospital, indicando a atuação em dois modelos de gestão: Modelo de Processos Internos e Modelos das Metas Racionais. Percebe-se também que o papel de negociador é o menos exigido para a atuação desses enfermeiros, seguido dos papéis de inovador, coordenador, diretor e facilitador respectivamente.

Como o prescrito pode não ser o realmente efetivado na realidade organizacional investigada, segue-se a apresentação dos dados referentes às percepções da atuação do enfermeiro, segundo eles próprios e segundo os demais membros da equipe de enfermagem por meio das entrevistas.

\section{As competências gerenciais dos enfermeiros do hospital $X$}

Os dados oriundos das entrevistas estão apresentados em duas seções: dados demográficos e funcionais dos entrevistados e dados relativos às percepções de enfermeiros e de outros membros da equipe de enfermagem em relação ao exercício das funções gerenciais por parte dos primeiros, sendo que procedeu-se à análise das repostas à luz do modelo adotado, ou seja, indicando os papéis gerenciais correlatos, segundo Quinn et al. ${ }^{(8)}$.

Foram realizadas 10 entrevistas, sendo 4 com enfermeiros e 6 com outros membros da equipe de enfermagem (técnicos e auxiliares de enfermagem). Destes, 4 eram do sexo masculino e 6 do sexo feminino. Em relação à faixa etária, a maioria dos entrevistados (6 deles) possui idade igual ou superior a 36 anos. Quanto ao estado civil, 5 entrevistados eram casados e 5 solteiros. Ao se tratar de escolaridade, 4 possuiam ensino superior incompleto, 2 ensino médio completo, 2 ensino superior completo e 2 entrevistados possuíam especialização. Dentre os entrevistados, 6 eram enfermeiros e 4 técnicos de enfermagem. Dos enfermeiros entrevistados, todos exercem a função de enfermeiro (supervisor) no hospital. Já entre os técnicos de enfermagem, 2 exercem a função de auxiliar de enfermagem II e 2 a função de técnico em enfermagem. Em relação ao tempo de trabalho no hospital, percebe-se que metade dos entrevistados (5 deles) trabalham há mais tempo no hospital. Quanto ao tempo de atuação na função no hospital, 4 entrevistados estão na função de 1 a 5 anos, 2 de 6 a 10 anos, um de 16 a 20 anos, um há mais de 20 anos e outro de 11 a 15 anos. Quanto ao tempo de experiência na função exercida incluindo outras organizações, 3 entrevistados já atuam há mais de 20 anos, 2 de 16 a 20 anos, 2 de 11 a 15 anos, 2 de 6 a 10 anos, 2 de 1 a 5 anos.

A partir das entrevistas com os dois grupos (enfermeiros e outros membros da equipe de enfermagem), verificou-se, por meio das respostas dos enfermeiros abordados e segundo os papéis e competências correlatas do modelo de Quinn et al. ${ }^{(8)}$, que estes deveriam exercer mais os papéis de facilitador e monitor, pois o papel de produtor foi recursivamente citado e criticado em certos pontos de vista, principalmente como um papel que tem sido prioritário, mas que não representa a complexidade das atividades e do exercício da função no hospital onde a pesquisa foi realizada. Já para os outros membros da equipe de enfermagem, estes consideram que 
os enfermeiros deveriam exercer mais o papel de facilitador, voltando-se mais para aspectos assistenciais, fato que indica a fragmentação e a variedade de exigências da função gerencial exercida pelos sujeitos centrais desta pesquisa, cuja competência foi questionada em vários momentos, indicando a necessidade de se atuar em diversos papéis que exigem competências diversificadas. Observam-se os relatos de enfermeiros (ENF) e dos outros membros da equipe (OM):

... Poderia dar... delegar... poderia ter mais ação de delegação para que o enfermeiro possa é... dar mais assistência, e o enfermeiro também deveria se mais assim ... durante o trabalho, suporte é... mais... de conhecimento científico, ter mais treinamento né... (ENF1)

Bom, no sentido geral, o enfermeiro tem que ter papel tanto administrativo, organizar o seu setor, acompanhar os funcionários, é... toda a parte administrativa, manutenção de materiais, manutenção de equipamentos, tem que gerenciar o seu setor, e também não pode deixar o seu lado assistencial. Você tem o lado de atendimento ao paciente, procedimentos específicos do enfermeiro, a evolução diária, a anamnese, né... então seria todo esse trabalho, o administrativo com o assistencial. (ENF2)

Ter mais compromisso, mais responsabilidade, ser mais responsável com o que faz, ter atitudes, em direção a meIhorar o trabalho dos técnicos e de si próprio né... poder estar ajudando ao paciente nas necessidades dele, não ficar só atrás da mesa usando papel porque para mim isso é importante, mas não tanto quanto o cuidado mais próximo. (OM2)

É... eu acho que ele deveria ser menos autoritário e mais comunicativo com a equipe. (OM3)

... Eu penso que a enfermagem... o enfermeiro, ele deveria trabalhar em conjunto com os técnicos. Infelizmente né... na atualidade da enfermagem os enfermeiros estão ficando muito isolados... [...] Ah... atuar mais efetivamente [risos] ... na enfermagem mesmo. (OM4)

Assim, a percepção entre os entrevistados a respeito dos papéis e das competências gerenciais ideais do enfermeiro destoam do prescrito pelo hospital, ou seja, o hospital espera que eles ajam como monitores, produtores e mentores, enquanto os enfermeiros acreditam que deveriam agir como facilitadores e monitores e os outros membros da equipe indicaram o comportamento ideal cirscuncrito ao papel de facilitador, o que indica um desnível em termos de comportamentos esperados.

Em relação a como o enfermeiro é, efetivamente, a maioria dos enfermeiros respondentes consideram que os enfermeiros são mais burocráticos e menos assistenciais, o que enfatiza o papel de produtor. Apenas um enfermeiro relatou existir um equilíbrio entre as atividades administrativas e as assistenciais. Para os outros membros da equipe de enfermagem, estes também consideram que efetivamente os enfermeiros deste hospital são mais burocráticos e menos assistenciais, com com comportamentos voltados para o papel de monitor. Os relatos abaixo ilustram tais percepções e análises.

[...] a parte científica deixa um pouco a desejar e acaba a gente dando outras prioridades, e na parte assistencial procurando também dar o máximo, porém temos que realizar muitas atividades burocráticas, que impede a uma assistência mais efetiva. (ENF1)

Ele [...] fica por conta de burocracia, às vezes, até eu percebo que eles precisam, mas não da forma correta para lidar com o paciente [...]. Hoje eles estão falando muito do cuidado com o paciente e deixando a responsabilidade não muitas vezes diariamente na mão dos técnicos. (OM2)

Dentre os motivos da diferença entre como deveria ser e como realmente é o enfermeiro do hospital $X$, verificou-se que os interesses empresariais do hospital, na percepção dos entrevistados, exigem desses profissionais o exercício de atividades administrativas e burocráticas, enfatizando o papel de produtor, o qual foi alvo de inúmeras críticas pelos entrevistados. Os comentários abaixo ilustram os posicionamentos dos sujeitos:

Porque realmente a gente está em um hospital né... numa empresa privada e realmente empresa privada ela quer que o enfermeiro dê conta das duas coisas, tanto da parte assistencial quanto da parte burocrática. (ENF3)

Porque o hospital depende do financeiro, é necessário que o financeiro seja bom! (ENF4)

Em minha opinião, eu acho que dependendo da instituição, principalmente nos hospitais particulares, essa diferença existe, porque o hospital visa lucro, então... esse lucro né... tem que ser preocupação, a preocupação é de olhar a papeleta, mas nunca de ir no quarto saber se o técnico está errando ao dar um medicamento. (OM4)

Para ser um "enfermeiro competente", os enfermeiros consideram a importância de voltar-se para a equipe, do aprimoramento profissional por meio de educação continuada e da capacidade de conciliar as atividades administrativas e assistenciais. Os outros membros consideram como "enfermeiro competente" aquele que se volta para a equipe, o que corrobora a opinião da maioria dos entrevistados dos grupos. As dificuldades dos enfermeiros em se tornarem competentes, para a maioria dos entrevistados dos dois grupos, relaciona-se à pouca atenção dada à equipe e ao ambiente de trabalho. Observa-se, novamente, pouca ênfase ao papel de facilitador e a exigência do papel de produtor. Notam-se os relatos dos enfermeiros a respeito do "enfermeiro competente":

O enfermeiro competente é aquele que tem conhecimento do seu setor, que sabe das suas necessidades, que sabe dos 
seus pontos fracos que precisam melhorar [...], o processo é uma educação continuada tem sempre estar treinando os novatos [...], a meu ver, a competência de um profissional é ter o conhecimento do seu setor e trabalhar, ter plano de ações para estar melhorando aquilo que ele acha que está fraco, aquilo que ele pode estar melhorando tanto a nível é... estrutural que precisa melhorar no setor como o lado profissional. (ENF2)

Além de cuidar primeiramente dos seus técnicos, da sua equipe, cuidar também dos pacientes, fazer aquilo que compete a eles [...], ele assumir essa responsabilidade e não ter medo, não deixar por conta do técnico que é quem realmente se sente desamparado. (OM2)

É... tecnicamente, mais também um lado humano que às vezes falta muito, porque não somos só profissionais, somos seres humanos e isso não é levado em conta. (OM3)

Que seja responsável, que seja humano e que tenha pulso, que saiba é... como é que eu falo... que saiba... ver na hora quem está certo, na hora quem está errado, que saiba solucionar os problemas e que realmente esteja com vontade de solucionar os problemas. (OM5)

Considerando o total dos entrevistados, verifica-se que a maioria deles não considera os enfermeiros do hospital $X$ como competentes devido à pouca ênfase para o papel de facilitador e maior ênfase para o papel de produtor. Porém, os entrevistados consideram os enfermeiros competentes frente ao exercício do papel de monitor com vistas à vontade de querer fazer o melhor.

Eu acho que todos são, eu acredito que exista comprometimento, que exista vontade de querer fazer o seu melhor, para mim assim... eu tento buscar isso né... é... tanto a nível aqui dentro de melhorias como mesmo de fora, de estudar, de procurar conhecimentos... (ENF2)

Deixam a desejar. Porque realmente, na minha opinião, eles, não, é... ouvem a equipe e não consegue liderar uma equipe como deveria ser. (OM1)

[...] quando tem um procedimento de maior responsabilidade, eu vejo que eles se esquivam, arrumam uma desculpa e deixa a responsabilidade na mão do técnico, onde fica a sobrecarga, né... (OM2)

Diante dessa realidade, convém elucidar o que os enfermeiros têm feito para serem competentes e reconhecidos como tal. Ao responderem, dois enfermeiros relatam que, para ser um "enfermeiro competente", esses profissionais voltam-se para a equipe no sentido de entrosar e esclarecer a equipe; dois responderam que é por meio de educação continuada que o enfermeiro torna-se "competente"; dois consideram que o enfermeiro tem de dar conta do serviço burocrático e ao mesmo tempo da assistência. Para os outros membros da equipe de enfermagem, três deles consideram que os enfermeiros voltam-se para a equipe. A maioria do total de entrevistados (5 deles) respondeu que, para se tornarem competentes, os enfermeiros devem voltar-se para a equipe.

Acima de tudo educação continuada, buscando sempre aprimorar, estudando, lendo, buscando novos cursos, novos conhecimentos e aqui dentro, estar desenvolvendo projetos de trabalho... (ENF2)

Eu procuro administrar o meu tempo nas duas partes, no administrativo e no assistencial. (ENF4)

É eu acho que é... tentar resolver os problemas que têm no setor relacionado à equipe, a doentes, a tudo né... (OM5)

Tem enfermeiros que buscam o conhecimento, às vezes pergunta dúvidas, pede para a gente estudar e fala também que vai estudar para tirar as dúvidas da gente se ele não souber. Mas temos também os que não preocupam não, não sabem mas também não estão nem aí... (OM6)

Em relação às dificuldades no processo em questão, ou seja, dos enfermeiros se tornarem competentes, as intercorrências ocorridas no plantão, como equipamentos que estragam e falta de funcionários, tornam-se um dificultador na percepção de dois dos enfermeiros. Um enfermeiro considera que é a pouca atenção para a equipe por parte do hospital em relação ao ambiente e à demanda exigida, devendo haver uma preocupação em "desestressar" as pessoas. Dois dos outros membros da equipe de enfermagem entrevistados relatam que os dificultadores são a pouca atenção para a equipe e outros dois consideram a falta de interesse por parte dos enfermeiros o grande dificultador do processo de formação de suas competências.

Como a maioria dos entrevistados respondeu que a pouca atenção dada à equipe e o ambiente de trabalho são os dificultadores para os enfermeiros tornarem-se competentes, percebe-se que a gestão das competências desses profissionais está atrelada às suas próprias capacidades e à forma de organização do seu trabalho na organização em que se encontram inseridos. Observam-se os relatos abaixo:

Competente! Eu assim eu sinto uma falta assim de treinamento né... [...] nesse ambiente... precisa ter alguma coisa para desestressar as pessoas... (ENF1)

Eu acho que a maior dificuldade são as intercorrências dentro do plantão, porque não existe uma rotina preestabelecida dentro do meu trabalho, [...] um funcionário faltou... (ENF2)

O tempo, para conseguir conciliar as duas partes... (ENF4)

[...] ouvir mais a equipe e também o seguinte: elaborar novas estratégias hospitalares para realmente ter esse resultado que não é alcançado ainda. (OM1) 
Se preocupar realmente com o quinto dia útil, é o que é importante para um enfermeiro hoje, saber que ele está empregado e que está ganhando [...] (OM2)

É exigido dele a burocracia, de estar preocupado sempre com o equipamento, com o papel, com coisas que não tem tanta importância de antes, de ver isso tudo, tem que cuidar do ser humano. (OM2)

Eles têm muitas coisas para fazer dentro do hospital e ele deve ter algum tempo, mas não busca né, não sei por qual o motivo que ele não busca... (OM6)

Quanto à contribuição do hospital para a formação e o desenvolvimento das competências do enfermeiro, percebe-se uma certa diversidade em relação às respostas: dois enfermeiros e dois membros relatam que o hospital contribui e dois enfermeiros e um membro relatam que o hospital contribui pouco. No que diz respeito à opinião dos outros membros da equipe de enfermagem, três consideram que o hospital não contribui. Essa contribuição está relacionada aos treinamentos oferecidos; porém, diante dos relatos, observa-se que os outros membros não sabem ou não têm uma noção a respeito de qual competência será desenvolvida por meio de qualquer recurso.

Eu acredito que sim, porque o hospital fornece o material de trabalho, [...] ele me dá o treinamento, ele me dá suporte, se eu tenho uma dúvida, eu tenho a quem recorrer para tirar essa dúvida, né... eu acho que a outra parte compete à própria pessoa de ir buscar né... buscar o treinamento, como uma pós-graduação ou outros cursos paralelos né... e isso o hospital não te dá, não. (ENF2)

Contribui, eles estão sempre dando curso, eles estão sempre dando palestra, eles estão sempre procurando meio de incentivar os enfermeiros a aprender mais... a estar mais próximo. [...] eu não tenho essa certeza porque são a portas fechadas. (OM2)

Não, eu acho que não contribui muito não, porque eles pedem para eles assim... umas coisas que não tem muito haver né... com a realidade da enfermagem. (OM6)

Em relação a como os enfermeiros se vêem no hospital, três deles disseram que "sem tempo"; dentre os membros da equipe, um respondeu que os enfermeiros se sentem como muito importantes e competentes, um respondeu que se sentem recuados e inseguros, um os vê como sobrecarregados, um os percebem como "estar em círculo" (sem sair do lugar) e um respondeu que se sentem sem visão do todo e como inferiores. Os relatos a seguir são ilustrativos a esse respeito:

[...] nós enfermeiros vamos seguindo essas normas, [...] o espaço para a gente criar é pouco, é pouco! [...] aí a gente fica sem tempo porque a gente... há muitas tarefas, entendeu? (ENF1)
Sempre com medo, é... insegurança, é inseguro a maioria.. sempre... o que eu ouço dizer, é que sempre tem aquele medo do "ser mandado embora" amanhã. [...] eles têm vontade de dizer alguma coisa que possa acrescentar, mais o medo é maior. (OM2)

Bom, pelo que eu converso com alguns que é a maioria, todos assim... se vêem de uma forma assim... que eles estão naquele círculo ali... né... que não sai daquele lugar, só isso! (OM4)

Como os outros membros da equipe de enfermagem vêem o enfermeiro do hospital $X$, na percepção dos entrevistados, segundo os enfermeiros, há divergências de opiniões e cada um dos entrevistados apresenta uma visão: como chefe, como burocráticos, como aquele que oferece suporte e esclarece dúvidas da equipe, e também como "apagador de incêndios". Para os outros membros da equipe, dois deles consideram que os enfermeiros são vistos como chefe. Observam-se os trechos selecionados das entrevistas que versam sobre como os outros membros da equipe de enfermagem veem os enfermeiros, nas percepções de ambos os grupos entrevistados:

Olha! ... eles vêem é... os enfermeiros... eles fazem muito trabalhos administrativos, é... a gente faz muita conferência né... [...] a gente tem que fazer um acompanhamento deles, para a gente é... avaliar, é... eu acho que eles vêem a gente assim, como gente administrativa com muita atividade administrativa. (ENF1)

Eu acredito que o enfermeiro aqui é um suporte, porque o técnico em tudo, ele tem comparando o supervisor daquela unidade, então se ele tem uma dúvida é a ele que vai recorrer, ele quer é... ter alguma explicação sobre procedimentos, alguma coisa que ele precisa saber. (ENF2)

Eu acho que eles vêem o enfermeiro tipo um apagador de incêndio, qualquer incendiozinho que começa... e eles já estão chamando o enfermeiro, acham que o enfermeiro é só para apagar o incêndio. (ENF3)

Que eles têm chefia, a mesma de cobrança. É isso... (ENF4)

Nesse setor, é uma equipe muito boa, que a gente resolve os nossos problemas aqui e tenha ajuda mútua, agora tem setores que é tipo assim... ela é minha chefe, ele é meu chefe, e eu sou o técnico. (OM5)

Em relação a como é o relacionamento com os enfermeiros do hospital, observa-se que três enfermeiros responderam que o relacionamento é bom e um afirmou que é tranquilo, o que reflete um relacionamento positivo entre a equipe de enfermeiros. Para os outros membros da equipe de enfermagem, quatro informam que o relacionamento é ótimo, um que é bom e outro, tranquilo, o que também revela um relacionamento positivo entre os outros membros da equipe de enfermagem e os enfermeiros. Nota-se que a opinião dos outros membros da equipe de enfermagem justifica-se pela 
possibilidade de expor suas necessidades, tirar dúvidas e conversar. Observam-se os relatos:

[...] a gente se encontra, conversam um pouquinho né... depois cada um vai para o seu setor né, para resolver, para dar andamento ao trabalho. (ENF1)

É super tranquilo, todo mundo é bacana, gente boa, é super tranquilo. (ENF3)

\section{Ótimo! Graças a Deus... com todos! (OM2)}

Oh... eu nesses 22 anos eu nunca tive problemas de relacionamento, com os enfermeiros eu tento fazer tudo da melhor maneira possível e assim mesmo na hierarquia que eu sempre sou subordinado ao enfermeiro, então a gente tem que saber né... as rotinas, as normas todas. (OM4)

Eu me relaciono muito bem com os enfermeiros, com todos os enfermeiros, tenho um diálogo muito aberto, sempre exponho as minhas necessidades, falo com eles aquilo que eu tenho dúvidas, sempre estou aberto a mudanças com eles, eles chegam para mim para questionar as coisas e eu também estou aberto a escutar e assim eles também né... (OM6)

Por fim, como é o relacionamento com os outros membros da equipe de enfermagem, os enfermeiros apontam um relacionamento positivo com os demais e vice-versa; um membro da equipe de enfermagem relata ser "mais ou menos". Os enfermeiros justificam esse relacionamento pela interatividade e por estarem próximos aos outros membros. Apesar de o relacionamento dos outros membros da equipe de enfermagem com os enfermeiros ser positivo, um membro relata que seu relacionamento com o profissional do mesmo grupo é melhor do que com os enfermeiros, apesar de ter diálogo, amizade, interatividade e companheirismo. Quanto ao relacionamento com os enfermeiros do hospital, verificou-se, nos dois grupos, um relacionamento positivo; porém, um membro da equipe de enfermagem frisou ter um relacionamento mais positivo com os profissionais de seu próprio grupo. Para ilustrar os achados, seguem-se relatos que pautam a análise:

Procuro ter um bom relacionamento né... o mais próxima deles né... o mais possível, porque isso é essência.I (ENF1)

Muito bom também, a equipe é muito boa, todo mundo muito interessado, muito bom! (ENF3)

Graças a Deus... me dou muito... muito... muito bem mesmo! (OM2)

Mais ou menos [risos] todo mundo estressado, e irritado e a maioria sem educação, infelizmente! (OM3)

O meu relacionamento é ótimo com eles! É até melhor que com os enfermeiros, a gente tem bastante diálogo, bastante amizade, comunicação, interatividade, companheirismo. (OM6)

Quanto aos resultados apresentados e analisados, verificou-se que os papéis de monitor, produtor, mentor e suas respectivas competências, constituem as exigências do hospital $X$ em relação às funções dos enfermeiros explicitadas nas descrições de cargos e competências, no qual predomina o papel de monitor. Considerando o modelo de Quinn et al. ${ }^{(8)}$, verificou-se que o modelo de gestão adotado pelo hospital está mais direcionado para o controle do que para a flexibilidade. Em relação aos outros papéis prescritos pelo hospital, percebe-se que o papel de negociador é o menos exigido, seguido pelos papéis de inovador, coordenador, diretor e facilitador, respectivamente.

Em relação ao prescrito, verificou-se que os enfermeiros não exercem efetivamente o papel de monitor conforme exigido pela descrição de cargos e competências do hospital. Já os papéis de negociador e inovador corroboram as exigências do hospital no que diz respeito à pouca ênfase dada a esses papéis. Os outros membros da equipe de enfermagem consideraram que os enfermeiros exercem uma regularidade no exercício dos papéis gerenciais de Quinn et al. ${ }^{(8)}$, porém o papel de inovador é o menos efetivo na opinião desse grupo de profissionais. Quando comparadas as percepções dos dois grupos, também se verificou que o papel de negociador foi pouco efetivo, porém o papel de produtor foi enfatizado na junção dos grupos.

O papel de coordenador foi visto como um papel importante para os enfermeiros como característica para um "enfermeiro competente"; porém, na descrição dos cargos do referido hospital, esse papel não é tão enfatizado. Na visão deles, procuram exercer o papel de monitor, que é o papel prioritário exigido na descrição de cargos, mas é visto que esse papel não é suficientemente executado principalmente na percepção dos outros membros da equipe de enfermagem, que consideram que os enfermeiros, além do papel de monitor, deveriam exercer os papéis de mentor e facilitador. $\mathrm{Na}$ visão dos dois grupos, percebe-se uma carência maior da execução do papel de facilitador e menor para o papel de produtor.

Conclui-se que os enfermeiros do hospital X, apesar de apresentarem certa regularidade dos papéis gerenciais de acordo com o modelo de Quinn et al. ${ }^{(8)}$, deixam a desejar nos papéis de monitor e facilitador, visto que o papel de monitor é predominante na descrição de cargos do hospital; porém, o papel de produtor merece destaque, tanto na análise dos documentos do hospital, como também nos resultados com os grupos pesquisados.

Diante das diferenças de percepções entre enfermeiros e outros membros da equipe de enfermagem quanto ao que é exigido e o que é efetivamente realizado pelos enfermeiros, nota-se um degrau de validação das competências destes últimos, já que o conceito de competência engloba o reconhecimento por terceiros ${ }^{(11,18)}$. Em face de tais considerações, algumas questões relativas ao processo de formação e desenvolvimento de competências se fazem presentes, como é o caso da contribuição dada pelas instituições de ensino 
superior que formam (ou pelo menos habilitam) tais profissionais para o exercício da Enfermagem.

\section{CONSIDERAÇÕES FINAIS}

Diante do exposto, ressalta-se a importância de congruência e, daí, de adequação dos papéis que vêm sendo idealizados e efetivamente realizados pelos enfermeiros, considerando-se os três atores envolvidos, a saber, o hospital $\mathrm{X}$, os enfermeiros e os outros membros da equipe de enfermagem, visando um equilíbrio maior entre o ideal e o real, principalmente nos papéis de monitor, mentor e facilitador.

Tendo em vista a limitação de que o estudo se deu em um único hospital privado, percebe-se a necessidade de ampliar a pesquisa a outros hospitais privados e, também, à rede pública, com vistas a comparações e possíveis generalizações que forneçam subsídios para melhorias que podem abraçar não só tais instituições de saúde e aprimorar as práticas pedagógicas de formação e desenvolvimento de competências profissionais e gerenciais do enfermeiro, em termos de ampliar o escopo de políticas e práticas de gestão de pessoas de modo a também agregar valor nesse sentido.

Da mesma maneira, estudos longitudinais são percebidos como fecundos, pois podem contribuir para o entendimento de peculiaridades que fazem diferença quanto à formação e ao desenvolvimento de competências gerenciais para o enfermeiro.

Note-se, ainda, que estender a pesquisa a outros atores que transitam no tipo de organização investigada - hospital - e contribuem para a qualidade da assistência prestada, como os outros profissionais da equipe multidisciplinar (médicos, nutricionistas, fonoaudiólogos, fisioterapeutas etc.), além dos próprios pacientes atendidos, pode também somar nesse processo de convergência de papéis, de modo a fortalecer a autoimagem dos enfermeiros e a própria profissão de Enfermagem, dadas as competências peculiares exigidas no seu exercício.

\section{REFERÊNCIAS}

1. Petrilli Filho JF, Martins DC. O programa especial de treinamento na formação do profissional de enfermagem do novo milênio: relato de experiência. Rev Lat Am Enferm 2001; 9(4): p. 91-3.

2. Felli VEA, Peduzzi M. O trabalho gerencial em enfermagem. In: Kurcgant P, coordenadora. Gerenciamento em Enfermagem. Rio de Janeiro: Guanabara Koogan; 2005. p. 1-13.

3. Arone EM, Cunha ICKO. Avaliação tecnológica como competência do enfermeiro: reflexões e pressupostos no cenário da ciência e tecnologia. Rev Bras Enferm 2006; 59(4): 18-26.

4. Brito MJM, Melo MCOL, Monteiro PRR, Costa JO. Interfaces das mudanças hospitalares na ótica da enfermeira-gerente. RAE 2004; 44(Edição Especial Minas Gerais): 34-46.

5. Brito MJM. A configuração identitária da enfermeira no contexto das práticas de gestão em hospitais privados em Belo Horizonte [tese]. Belo Horizonte (MG): Faculdade de Ciências Econômicas, Universidade Federal de Minas Gerais; 2004.

6. Jorge MSB, Freitas CHA, Nóbrega MFB, Queiroz MVO. Gerenciamento em enfermagem: um olhar crítico sobre o conhecimento produzido em periódicos brasileiros (2000-2004). Rev Bras Enferm 2007; 60(1): 81-6.

7. Davel E, Melo MCOL. Singularidades e transformações no trabalho dos gerentes. In: Davel E, Melo MCOL, organizadores. Gerência em ação: singularidades e dilemas do trabalho dos gerentes. Rio de Janeiro: Fundação Getúlio Vargas; 2005. p. 29-65.

8. Quinn RE, Faerman SR, Thompson MP, McGrath MR. Competências gerenciais: princípios e aplicações. 3a. ed. Rio de Janeiro: Elsevier; 2003.
9. Ruas RL. Desenvolvimento de competências gerenciais e contribuição da aprendizagem organizacional. In: Fleury MTL, Oliveira Júnior MM, organizadores. Gestão estratégica do conhecimento. São Paulo: Atlas; 2001. p. 243-269.

10. Vergara SC, Branco PD. Competências gerenciais requeridas em ambiente de mudança. In: Anais do $19^{\circ}$. Encontro Anual da ANPAD; 1995; João Pessoa (PB), Brasil. Pernambuco: ANPAD, 1995.

11. Rhinesmith $\mathrm{SH}$. Guia gerencial para a globalização. Rio de Janeiro: Berkeley; 1993.

12. Paiva KCM. Gestão de competências e a profissão docente: um estudo em universidades no estado de Minas Gerais [tese]. Belo Horizonte (MG): Faculdade de Ciências Econômicas, Universidade Federal de Minas Gerais; 2007.

13. Vergara SC. Projetos e relatórios de pesquisa em administração. 4a. ed. São Paulo: Atlas; 2003.

14. Goldenberg M. A arte de pesquisar: como fazer pesquisa qualitativa em ciências sociais. Rio de Janeiro: Record; 1997.

15. Collis J, Hussey R. Pesquisa em Administração: um guia prático para alunos de graduação e pós-graduação. 2a. ed. Porto Alegre: Bookman; 2005.

16. Melo MCOL. Estratégias do trabalhador informático nas relações de trabalho [tese]. Belo Horizonte (MG): Faculdade de Ciências Econômicas, Universidade Federal de Minas Gerais; 1991.

17. Bardin L. Análise de Conteúdo. Lisboa: Edições 70; 2006.

18. Fleury ACC, Fleury MTL. Estratégias empresariais e formação de competências. São Paulo: Atlas; 2001. 